\title{
Effect of the choice of food composition table on nutrient estimates: a comparison between the British and American (Chilean) tables
}

\author{
V Garcia ${ }^{1,2, *}$, RJ Rona ${ }^{1}$ and S Chinn ${ }^{1}$ \\ 'Department of Public Health Sciences, King's College London, 5th Floor, Capital House, 42 Weston Street, London \\ SE 1 3QD, UK: ${ }^{2}$ Department of Nutrition, Faculty of Medicine, University of Chile, Santiago, Chile
}

Submitted 30 April 2003: Accepted 5 August 2003

\begin{abstract}
Objective: To determine the level of agreement between the American (Chilean) and British food composition tables in estimating intakes of macronutrients and antioxidants.

Design, setting and subjects: Information based on a food-frequency questionnaire with emphasis on antioxidants was collected from 95 Chileans aged 24-28 years. Nutritional composition was analysed using the British table of food composition and the American table of food composition modified by Chilean food items. Mean differences and limits of agreement (LOAs) of estimated intake were assessed.

Results: Mean differences between the two tables of food composition ranged from 5.3\% to $8.9 \%$ higher estimates when using the American (Chilean) table for macronutrients. For micronutrients, a bias towards a higher mean was observed for vitamin E, iron and magnesium when the American (Chilean) table was used, but the opposite was observed for vitamin A and selenium. The intra-class correlation coefficient (ICC) ranged from 0.86 (95\% confidence interval (CI) $0.81-0.91)$ to 0.998 (95\% CI 0.995-1.00), indicating high to excellent agreement. LOAs for macronutrients and vitamins $\mathrm{A}$ and $\mathrm{C}$ were satisfactory, as they were sufficiently narrow. There was more uncertainty for other micronutrients.

Conclusion: The American table gives relative overestimates of macronutrients in comparison to the British table, but the relative biases for micronutrients are inconsistent. Estimates of agreement between the two food composition tables provide reassurance that results are interchangeable for the majority of nutrients.
\end{abstract}

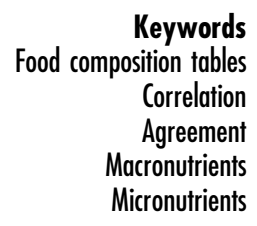

The quality of food consumption and food composition data must be considered simultaneously for the analysis and interpretation of food intake in a population ${ }^{1,2}$. The quality of food composition data is greatly influenced by the control of variation in food composition, the accuracy in the description of nutrients, the methods of analysis and the mode of data expression ${ }^{3}$.

Problems with these elements make the food composition table a known major source of error in the estimation of nutrient intakes ${ }^{4}$. Differences and errors are also found when different nutrient databases based on the same national food composition table are compared ${ }^{5}$. International comparisons are more complex, as other differences are added. The most common are related either to the foods (different systems to name, group and describe them) or to the analysis (insufficient description of foods, missing values, ambiguous nomenclature and different chemical analytical methods for specific nutrients) ${ }^{6,7}$. These lead not only to food composition databases that differ substantially in form, content and relative quality, but also to bias in the interpretation of diet-disease relationships ${ }^{7}$.

A large amount of work has been done to produce more detailed and homogeneous food composition tables, which has provided some guidelines on the organisation and content of nutritional databases, methods for compiling tables and procedures for the accurate international exchange of data ${ }^{8,9}$. However, many countries, both developed and developing, still lack appropriate national food composition tables ${ }^{6,10-12}$. This has motivated the use of tables from other countries with more accurate or complete information, either as the local database reference for nutritional data analysis ${ }^{11}$ or for the substitution of missing values for specific nutrients ${ }^{12}$.

Some advantages may be extracted from using other tables, such as an improvement in the quality of nutritional analysis and less expense and loss of time than in the production of new tables ${ }^{12}$. However, comparability is a 
major issue, as local conditions involved in the production of foods will certainly affect their chemical composition ${ }^{13}$. Furthermore, the identification of foods might be particularly difficult for countries that are very rich in 'typical' foods or meals, and where imputed values taken from similar foods may be of uneven reliability ${ }^{12-14}$.

Many researchers in the field have direct experience with only one set of tables of food composition. There is little knowledge about the extent to which the results of an analysis may be coloured by the peculiarities of a particular set of tables. This paper addresses the question of whether the choice of a particular set of tables may have an impact on the results by assessing the levels of agreement and comparability of estimates using two nutritional databases: the first based mainly on the American table of food composition and including some Chilean nutritional data, the other based on the British table of food composition.

\section{Subjects and methods}

\section{Population}

The study was carried out in a sub-sample of 95 people, as part of a cohort study that aimed to explore the relationship between diet and asthma in a semi-urban area of Central Chile. Adults between 24 and 28 years old were selected to complete a food-frequency questionnaire (FFQ) with special emphasis on the consumption of antioxidants and fatty acids to determine the dietary intakes of these foods.

\section{Food-frequency questionnaire}

The quantitative FFQ was designed to obtain information on the consumption of antioxidants and fatty products during the past month. It included a variety of foods that cover around $90 \%$ of the common food intake in the Chilean population ${ }^{15}$.

The FFQ was divided into 12 food groups, containing a total of 65 items: fruits with high levels of vitamin $\mathrm{C}$ and flavonoids; vegetables rich in vitamins $\mathrm{A}, \mathrm{C}$ and $\mathrm{E}$ and flavonoids; legumes; animal meat (chicken, beef, poultry, pork); fish with high levels of fat (salmon, tuna) and shellfish; eggs; cereals (bread, pasta, rice, sweet biscuits, cakes); fatty products (offal, margarine, butter); dairy foods (whole or skimmed milk, cheese, yoghurt, milky desserts); sugar, ham, honey, sweets; red wine; and nonalcoholic drinks such as juices, tea and coffee. An additional question was added on the consumption of nutritional supplements.

For each group of food, the frequency of consumption was recorded as daily, weekly, fortnightly or monthly. Food intake was first recorded in the FFQ as 'standard portion sizes' (teaspoons, cups, units, etc.). These portions were then translated into grams for each food item. After calculating the total grams consumed daily, the data were analysed using each food composition database.

\section{Food composition tables (databases)}

To obtain estimates using the American (Chilean) database, data on food consumed were analysed with a computer program based on information provided by the US Department of Agriculture's (USDA) Nutrient Database, which includes information on energy and 28 nutritional components of more than 5000 foods $^{16}$. The surveys that contributed to this database were the Nationwide Food Consumption Survey and the Continuing Survey of Food Intakes by Individuals conducted by the USDA, and the National Health and Nutrition Examination Survey conducted by the Department of Health and Human Services. This source of nutritional composition has been the most common nutritional reference for dietary surveys in Chile ${ }^{17,18}$.

For some Chilean staple foods that do not appear in the American database, and for specific supplementations, chemical nutritional analysis provided by the eighth edition of the Chilean Table of Foods Chemical Composition $^{19}$ (1992 version) was added. It contains a description of macro- and micronutrients for a wide range of foods produced or harvested in the country and for traditional Chilean meals.

For the purposes of this study, the Chilean table was considered for the nutritional composition of the following foods:

- Bread, which alone represents on average almost $40 \%$ of the energy intake of the Chilean population ${ }^{17}$. Wheat flour has a particular composition, since in 1965 a national compulsory fortification system including vitamin $\mathrm{A}$, niacin and riboflavin was approved $^{15}$.

- Updated content of omega $6(n-6)$ and omega $3(n-3)$ fatty acids (poly- and monounsaturated) ${ }^{20}$.

The estimates using the British table of food composition were obtained using the program IDA (Integrated Dietary Analysis; IDA Ltd, London, 1997), which is based on the Royal Society of Chemistry's Database 1988-1995 plus all available supplements and appendices $^{21}$. Many of the values included in the British tables were derived from a series of analytical studies commissioned by the Ministry of Agriculture, Fisheries and Food. These studies were done by purchasing samples of foods in local or regional shops or other retail outlets, or incorporated other validated information from the literature on foods of similar characteristics to those found in Britain.

Estimates of nutrients using each of the two sets of food composition tables were independently obtained, in Chile for the USA (Chile) table of food composition and in the UK for the British table of food composition. Although the British tables are not adapted to the peculiarities of the Chilean diet this did not constitute a major problem, as only one item of food, longaniza, was unavailable and finally entered as 'sausage'. 


\section{Recommendations}

For the nutritional recommendations the reference values used were those given by the British Department of Health $^{22}$, based on the World Health Organization recommendations ${ }^{23}$, which apply to the Chilean population included in this survey. The Estimated Average Requirement (EAR) is defined as the notional mean requirement, assuming that the distribution of requirements for a nutrient in a group of individuals is symmetrical.

\section{Statistical analysis}

Mean intakes of energy and nutrients estimated using the American (Chilean) nutritional database were compared with those obtained from the British using the paired $t$-test.

Agreement between estimates was expressed by limits of agreement (LOAs), as recommended by Bland and Altman $^{24}$. The Bland-Altman method provides an absolute measure of agreement, in units of each measurement. This does not allow easy comparison across nutrients that have different units of measurement and variation in intake. The intra-class correlation coefficient (ICC) is a measure of relative repeatibility ${ }^{25}$. If the two estimates from the American (Chilean) table and the British table measure the same quantity then they should be replicated, so the ICC was calculated to measure relative agreement. It is suggested that an ICC of 0.6 is the lowest limit of a useful measurement ${ }^{26}$.

Pearson's correlation coefficient was calculated to assess the linear relationship between the two estimates for each individual of the same measurement reported using the two databases. It is an inappropriate measure of agreement $^{24}$, but many researchers have used it for this purpose and we provide it here to show the difference.

\section{Results}

Nutritional intakes of total energy, macro- and micronutrients, as estimated using each database, are presented in Table 1. The protein and micronutrient intakes of participants were well above the EAR values, while the consumption of saturated fatty acids was below the EAR. The medians estimated from the American (Chilean) table were consistently higher for total energy and macronutrients than those from the British table. The differences were particularly large for carbohydrates and protein. In the subgroups of fatty acids, only the intake of polyunsaturated fatty acids (PUFA) was higher when using the American (Chilean) table.

Differences in median values of micronutrients based on estimates from the two tables of food composition were less consistent (Table 1). Medians for vitamin E, iron and magnesium were higher when estimates were based on

Table 1 Energy and nutrient intakes according to the American (Chilean) and British tables of food composition. Values are expressed as median (interquartile range)

\begin{tabular}{|c|c|c|c|}
\hline Nutrient & $\mathrm{EAR}^{*}$ & American (Chilean) & British \\
\hline Energy (kcal day ${ }^{-1}$ ) & 2245 & $2358(1941-3434)$ & $2250(1785-3325)$ \\
\hline $\begin{array}{l}\text { Carbohydrates } \\
\% \text { TEI } \\
\text { g day }^{-1}\end{array}$ & $\begin{array}{c}60 \\
337.2\end{array}$ & $\begin{array}{c}58.7 \\
351.6(288.8-513.5)\end{array}$ & $\begin{array}{c}57.7 \\
320.0(250.1-482.2)\end{array}$ \\
\hline $\begin{array}{l}\text { Protein } \\
\% \text { TEl } \\
\text { g day }^{-1}\end{array}$ & $\begin{array}{l}10 \\
50.2\end{array}$ & $101.2(73.1-142.7)$ & $89.0(64.2-135.1)$ \\
\hline $\begin{array}{l}\text { Total fat } \\
\text { \% TEI } \\
\text { g day }^{-1}\end{array}$ & $\begin{array}{l}30 \\
75\end{array}$ & $\begin{array}{c}27.9 \\
73.4(52.7-112.5)\end{array}$ & $\begin{array}{c}28.4 \\
72.1(50.6-103.4)\end{array}$ \\
\hline $\begin{array}{l}\text { Saturated fatty acids } \\
\% \text { TEI } \\
\text { g day }^{-1}\end{array}$ & $\begin{array}{l}12 \\
35\end{array}$ & $\begin{array}{c}7.5 \\
18.1(12.7-28.8)\end{array}$ & $\begin{array}{c}8.0 \\
19.4(13.1-28.0)\end{array}$ \\
\hline $\begin{array}{l}\text { Monounsaturated fatty a } \\
\% \text { TEI } \\
\text { g day }^{-1}\end{array}$ & $\begin{array}{l}10 \\
25\end{array}$ & $\begin{array}{c}10.3 \\
25.5(17.6-42.6)\end{array}$ & $\begin{array}{c}11.1 \\
27.4(18.4-41.2)\end{array}$ \\
\hline $\begin{array}{l}\text { Polyunsaturated fatty aci } \\
\% \text { TEI } \\
\text { g day }^{-1}\end{array}$ & $\begin{array}{r}6 \\
15\end{array}$ & $\begin{array}{c}7.6 \\
20.9(15.5-31.1)\end{array}$ & $\begin{array}{c}7.0 \\
17.3(12.5-25.3)\end{array}$ \\
\hline $\begin{array}{l}\text { Vitamin A }\left(\mu \mathrm{g} \mathrm{day}^{-1}\right) \\
\text { Vitamin C }\left(\mathrm{mg} \mathrm{day}^{-1}\right) \\
\text { Vitamin E }\left(\mathrm{mg} \mathrm{day}^{-1}\right) \\
\text { Iron }\left(\mathrm{mg} \text { day }^{-1}\right) \\
\text { Magnesium }\left(\mathrm{mg} \mathrm{day}^{-1}\right) \\
\text { Selenium }\left(\mu \mathrm{g} \text { day }^{-1}\right) \\
\text { Zinc }\left(\mathrm{mg} \mathrm{day}^{-1}\right)\end{array}$ & $\begin{array}{c}650 \\
25 \\
5 \\
10.1 \\
225 \\
\text { ND } \\
6.4\end{array}$ & $\begin{array}{c}1503(940-2422) \\
158.8(105.1-280.7) \\
16.1(13.1-22.8) \\
18.1(14.0-25.3) \\
305.5(216.0-377.4) \\
98.4(72.4-143.2) \\
8.6(6.0-10.7)\end{array}$ & $\begin{array}{c}1597(1034-2465) \\
152.0(103.0-266.0) \\
15.6(12.4-22.0) \\
14.6(11.9-21.3) \\
280.9(189.7-349.6) \\
106.2(77.9-156.0) \\
9.0(6.3-11.1)\end{array}$ \\
\hline
\end{tabular}

EAR - Estimated Average Requirement; \%TEI - percentage of total energy intake; ND - not defined.

* The values given are means of the requirements for men and women. 
the American (Chilean) table, but vitamin A and selenium were higher when using the British table.

Table 2 shows the mean differences and LOAs for energy and nutrients. The mean differences and $P$-values between the estimates from the two tables of food composition confirm the results described in Table 1 . The bias towards higher values from the American food composition table, expressed as a percentage of the overall mean for each nutrient, varied from $5.2 \%$ for total fats to $8.7 \%$ for carbohydrates, but for PUFA was $15.6 \%$. The bias was also high for iron (19.0\%). LOAs are given for each nutrient. The LOAs are sufficiently narrow for most macronutrients, except PUFA. They were also narrow for vitamins $\mathrm{A}$ and $\mathrm{C}$. There is more uncertainty in the interpretation of the LOAs for iron, magnesium, selenium, zinc and vitamin E. Figure 1 gives examples of BlandAltman plots. The LOAs are narrow for the three nutrients, except that for selenium the discrepancy between food tables depended on the level of intake.

ICCs ranged between 0.86 for iron and 0.99 for vitamins A and C (Table 3). Although the ICCs are all very high they are highest for all macronutrients, except PUFA, and for vitamins A and C, confirming our impression from the LOA results. Pearson's correlation coefficient is also given; it ranged from 0.91 (zinc) to 0.99 (e.g. vitamin A) (Table 3), but is higher than the ICC and gives a misleading representation of agreement, particularly when relative bias was detected.

\section{Discussion}

\section{Main findings}

Higher estimates for macronutrients were observed when the American (Chilean) table was used. Mean differences for micronutrients were biased, but the direction of the bias was inconsistent. The ICC for each nutrient was very high, ranging from 0.86 to 0.99 , indicating - contrary to expectations - that the level of agreement between the two tables of food composition is excellent for most nutrients or at least satisfactory. The ICC estimates the between-individuals variance in relation to the total variance including error, and thus shows that crosssectional analysis of macro- and micronutrients in relation to diet should be relatively robust to the choice of database.

\section{Limitations}

Our study was based on an FFQ designed to estimate dietary intakes of specific antioxidants and only a limited number of foods were included. However, this FFQ gathers information on the most usual foods, and it represents more than $90 \%$ of the daily energy intake of the studied population ${ }^{15}$.

\section{Comparison with otber studies}

Food composition tables that have their own specific conversion factors for the determination of energy ${ }^{27,28}$ and use different methods for analysing carbohydrates ${ }^{16}$ may be a source of variation in the estimation of nutrients. In the case of the American and British tables, values for energy and macronutrients are expressed using the same units or at least units that are convertible (joules and calories, pounds and grams $)^{7,17,27}$. However, in the USDA food composition tables, carbohydrates are calculated including fibre, and digestibility is a factor taken into account when calculating conversion factors into energy $^{16}$. Instead, in the British table, available carbohydrates are expressed as monosaccharides and do not consider digestibility when converting into energy ${ }^{7,21}$, which could explain the different values obtained for energy and carbohydrates in our study. Other international comparisons have reported that nutritional

Table 2 Level of agreement for daily intakes of energy, macro- and micronutrients, according to Chilean (American) and British tables of food composition

\begin{tabular}{|c|c|c|c|c|c|}
\hline Nutrient & $\begin{array}{l}\text { Mean difference } \\
(95 \% \mathrm{Cl})\end{array}$ & $P$-value & Mean* & $\%$ biast & $\begin{array}{l}\text { LOA (reference } \\
\text { range for difference) }\end{array}$ \\
\hline Energy (kcal) & 182.1 (161.2 to 203.0$)$ & $<0.001$ & 2610.5 & 7.0 & -23.0 to 387.3 \\
\hline Carbohydrates (g) & 33.1 (28.4 to 37.8$)$ & $<0.001$ & 380.2 & 8.7 & -12.9 to 79.1 \\
\hline Protein $(g)$ & 9.5 (8.3 to 10.7$)$ & $<0.001$ & 106.2 & 8.5 & -2.5 to 21.6 \\
\hline Total fat $(\mathrm{g})$ & $4.3(3.3$ to 5.3$)$ & $<0.001$ & 81.8 & 5.2 & -5.5 to 14.2 \\
\hline Saturated fatty acids (g) & $0.14(-0.14$ to 0.7$)$ & 0.69 & 27.7 & 0.5 & -5.3 to 5.6 \\
\hline Monounsaturated fatty acids (g) & $-0.1(-0.7$ to 0.4$)$ & 0.33 & 31.1 & -0.3 & -0.6 to 5.7 \\
\hline Polyunsaturated fatty acids (g) & $3.2(2.7$ to 3.7$)$ & $<0.001$ & 20.5 & 15.6 & -1.8 to 8.3 \\
\hline Vitamin A (mg) & $-72.3(-81.2$ to -63.3$)$ & $<0.001$ & 1899.9 & -3.8 & -160.1 to 15.4 \\
\hline Vitamin C (mg) & $2.2(-1.0$ to 5.4$)$ & 0.90 & 228.5 & 1.0 & -29.5 to 33.9 \\
\hline Vitamin E (mg) & $0.8(0.4$ to 1.2$)$ & $<0.001$ & 17.5 & 4.6 & -3.2 to 4.9 \\
\hline Iron (mg) & 3.5 (3.0 to 3.9$)$ & $<0.001$ & 18.4 & 19.0 & -1.1 to 8.1 \\
\hline Magnesium (mg) & 20.6 (12.0 to 29.2 ) & $<0.001$ & 304.5 & 6.8 & -64.0 to 105.3 \\
\hline Selenium $(\mu \mathrm{g})$ & $-9.5(-12.1$ to -6.9$)$ & $<0.001$ & 115.2 & -8.3 & -35.0 to 15.9 \\
\hline Zinc (mg) & $-0.1(-0.4$ to 0.2$)$ & 0.24 & 9.0 & -1.1 & -3.1 to 2.9 \\
\hline
\end{tabular}

$\mathrm{Cl}$ - confidence interval; LOA - limit of agreement.

${ }^{*}$ Mean $=$ mean of two means estimated from the two food composition tables.

$\dagger \%$ bias $=$ mean difference divided by the mean. 


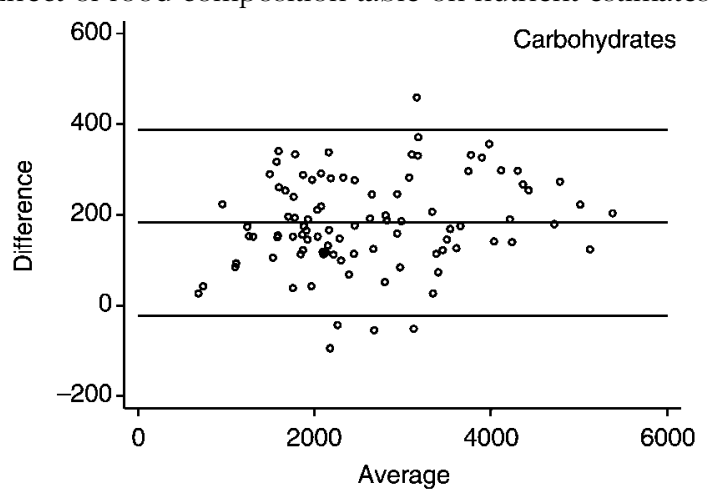

Limits of agreement (reference range for difference): -23.1 to 384.3 Mean difference: 182.1 (95\% $\mathrm{Cl} 161.2$ to 203.0 )

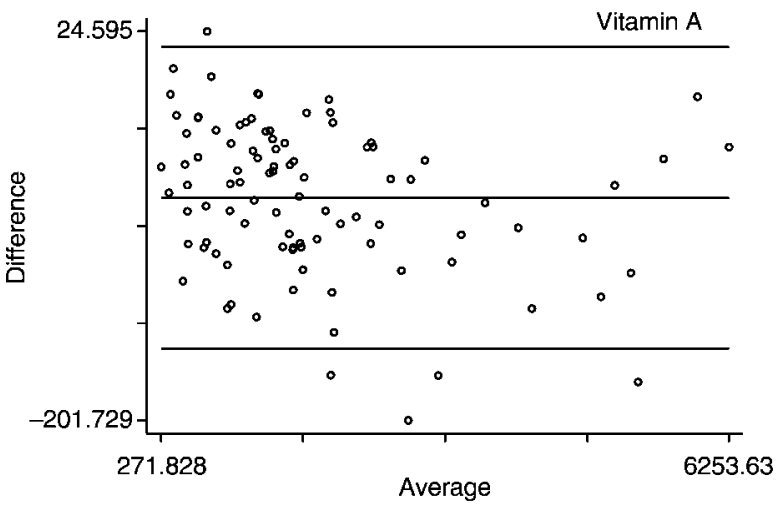

Limits of agreement (reference range for difference): -160.1 to 15.5 Mean difference: $-72.3(95 \% \mathrm{Cl}-81.2$ to 63.4$)$

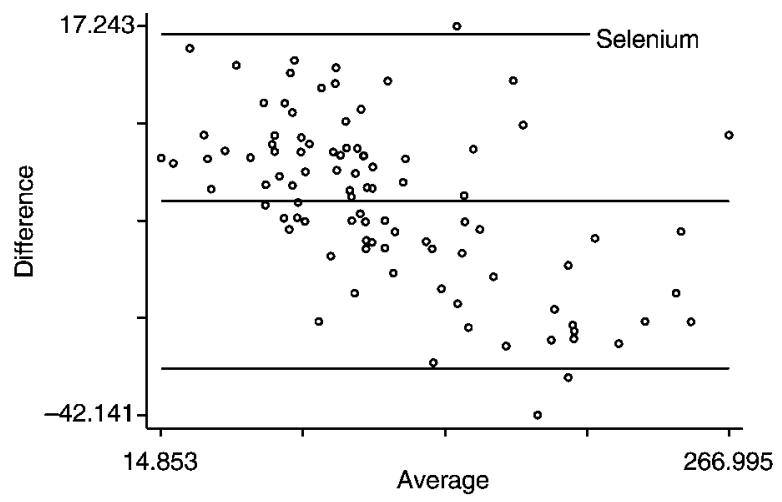

Limits of agreement (reference range for difference): -35.0 to 16.0 Mean difference: $-9.5(95 \% \mathrm{Cl}-12.1$ to 6.9$)$

Fig. 1 Bland-Altman plots of mean differences and limits of agreement for carbohydrates, vitamin $\mathrm{A}$ and selenium (the difference is given as the value using the American (Chilean) table of food composition minus the value using the British table of food composition). $\mathrm{Cl}$ - confidence interval

databases greatly influenced by the USDA data, like Central and South American tables ${ }^{7,29}$, have given values of carbohydrates up to $29 \%$ higher than those estimated using European databases, when comparing the same foods.

Problems related to the differences between methods for calculating energy and nutrients have been suggested as reasons for lack of comparability between food composition databases around the world. Although these
Table 3 Intra-class correlation coefficient and Pearson's correlation coefficient for energy, macro- and micronutrients

\begin{tabular}{lcc}
\hline Nutrient & $\begin{array}{c}\text { Intra-class correlation } \\
\text { coefficient }(95 \% \mathrm{Cl})\end{array}$ & $\begin{array}{c}\text { Pearson's } \\
\text { correlation } \\
\text { coefficient }\end{array}$ \\
\hline Energy & $0.98(0.97-0.98)$ & 0.99 \\
Protein & $0.96(0.95-0.98)$ & 0.99 \\
Carbohydrates & $0.97(0.95-0.98)$ & 0.98 \\
Total fat & $0.98(0.98-0.99)$ & 0.99 \\
Saturated fatty acids & $0.98(0.97-0.99)$ & 0.98 \\
Monounsaturated fatty acids & $0.98(0.98-0.99)$ & 0.98 \\
Polyunsaturated fatty acids & $0.92(0.89-0.93)$ & 0.97 \\
Vitamin A & $0.998(0.995-1.00)$ & 0.99 \\
Vitamin C & $0.995(0.992-0.998)$ & 0.99 \\
Vitamin E & $0.95(0.94-0.97)$ & 0.96 \\
Iron & $0.86(0.81-0.91)$ & 0.96 \\
Magnesium & $0.94(0.92-0.96)$ & 0.95 \\
Selenium & $0.95(0.94-0.97)$ & 0.98 \\
Zinc & $0.91(0.88-0.94)$ & 0.91 \\
\hline
\end{tabular}

$\mathrm{Cl}$ - confidence interval.

issues have been discussed since the $1940 \mathrm{~s}^{30}$, they still remain as unsolved issues when comparing nutritional databases ${ }^{3}$. National food composition tables are primarily aimed at providing nutrient data over time at a local level, so that they are not necessarily conceived to provide internationally comparable data. This has been shown in a large research study on food composition tables from nine European countries, where problems in common methods and definitions for some nutrients (folate, dietary fibre) or modes of expression (energy, protein, carbohydrates, carotenes, vitamins A and E) have not yet been resolved ${ }^{6}$. Given the number of reasons that can explain differences between tables of food composition, it is pleasing to note that our study, while confirming the bias between estimates from the British and American tables, shows a high level of agreement between the two. Thus the choice of food composition table, American or British, may not unduly affect the results in analytical studies.

It has long been recognised that estimate values for PUFA are difficult to harmonise when comparing nutritional databases. Frequent missing values of individual fatty acids and local conditions that determine variations in the chemical composition of fish and seafood (the primary source of PUFA) affect the comparability between food composition tables ${ }^{31}$. In addition, for the purposes of this research, we included updated Chilean data on the content of omega 3 and omega 6 fatty acids ${ }^{20}$, which directly reflects the chemical composition of foods extracted in the country, so they may differ from those values reported when using the British table. These reasons may partly explain our findings of higher reported values in the American (Chilean) table and the lowest reported ICC among the macronutrients.

In our study, values for minerals showed the least agreement among micronutrients. Differences in vitamins and minerals have been confirmed in another Latin American study comparing the amount of minerals found 
in vegetables and fruits to those values in the British and German food composition tables ${ }^{32}$. Food analyses from South America and Europe have demonstrated that the mineral content of foods is the most vulnerable to influence not only by the use of different methods, but also by environmental factors ${ }^{7,33}$. Climatic conditions, light, temperature and soil characteristics can greatly affect the growth rates of plants and therefore the final content of minerals. This may explain why the agreement between the estimates of food composition in our study was lower for metals.

It should be noted that the Pearson correlation is a measure of association and not of agreement ${ }^{24}$. In spite of this, it is the most common method used for assessing FFQ reproducibility. In fact, more than $90 \%$ of studies include only this analysis to compare dietary intake ${ }^{3}$, and it is wrongly inferred from a high correlation that the methods may be used interchangeably'. In our study, the ICC and Pearson correlation coefficient were not greatly different, but still the Pearson correlation would have provided a somewhat misleading reassurance in relation to iron and PUFA.

We conclude that there should be awareness that tables of food composition could be an important source of bias. Thus, comparison between studies that do not use the same table of food composition may be inappropriate. Methodological differences for determination of energy (including conversion factors), differences in supplementation policies as well as local environmental conditions influence nutritional values reported in tables of food composition. All of these characteristics can attenuate the level of association in aetiological studies. Taking on board all these caveats, the level of agreement between the two tables of food composition found in the present study was unexpectedly high.

\section{Acknowledgements}

We are indebted to Drs Patricia Bustos and Hugo Amigo for co-ordinating the data collection in Chile. We also thanks Mrs Ana Cristina Pinheiro for assessing nutrient compositions based on the American (Chilean) table of food composition and the fieldworkers who administered the FFQ. This project was funded by a grant of the Wellcome Trust.

\section{References}

1 Margetts BM, Nelson M. Overview of the principles of nutritional epidemiology. In: Margetts BM, Nelson M, eds. Design Concepts in Nutritional Epidemiology, 2nd ed. Oxford: Oxford University Press, 1997; 3-38.

2 Cade J, Thompson R, Burley V, Warm D. Development, validation and utilisation of food-frequency questionnaires - a review. Public Health Nutrition 2002; 5: 567-87.

3 Leclercq C, Valsta LM, Turrini A. Food composition issues implications for the development of food-based dietary guidelines. Public Health Nutrition 2002; 4: 677-82.
4 Dwyer JT. Future directions in food composition studies. Journal of Nutrition 1994; 124: 17835-85.

5 Lee RD, Nieman DC, Rainwater M. Comparison of eight microcomputer dietary analysis programs with the USDA Nutrient Database for Standard Reference. Journal of the American Dietetic Association 1995; 95: 858-67.

6 Deharveng G, Charrondiere UR, Slimani N, Southgate DAT, Riboli E. Comparison of nutrients in the food composition tables available in the nine European countries participating in EPIC. European Journal of Clinical Nutrition 1999; 53: $60-79$.

7 Polacchi W, Weisell R, Marroni S, Mazar I. Derivation of nutrient values for FAO Statistical Databases. Journal of Food Composition and Analysis 2002; 15: 515-22.

8 Schlotke F, Becker W, Ireland J, Møller A, Ovaskainen ML, Monspart J, et al. EUROFOODS recommendations for food composition database management and data interchange. Journal of Food Composition and Analysis 2000; 13: 709-44.

9 Ireland JD, Møller A. Review of international food classification and description. Journal of Food Composition and Analysis 2000; 13: 529-38.

10 Khalil JK. Food composition activities in developing countries: SAARCFOODS perspective. Journal of Food Composition and Analysis 2000; 13: 669-84.

11 Food and Agriculture Organization/LATINFOODS. Tabla de Composición de Alimentos de América Latina [online], 2000. Available at http://www.rlc.fao.org/bases/alimento.

12 Romieu I, Hernandez-Avila M, Rivera JA, Ruel MT, Parra S. Dietary studies in countries experiencing a health transition: Mexico and Central America. American Journal of Clinical Nutrition 1997; 65: 1159S-65S.

13 Slimani N, Charrondière R, van Staveren W, Riboli E. Standardization of food composition databases for the European Prospective Investigation into Cancer and Nutrition (EPIC): general theoretical concept. Journal of Food Composition and Analysis 2000; 13: 567-84.

14 Marletta L, Lucarini M, Ruggeri S, Carnovale E. Food composition databases in Italy: problems and perspectives Journal of Food Composition and Analysis 2000; 13: 611-8.

15 Chilean Ministry of Health. Dietary Guidelines for Chile. Santiago: Chilean Ministry of Health, 1996.

16 US Department of Agriculture, Agricultural Research Service. USDA National Nutrient Database for Standard Reference, Release 15 [online], 2002. Available at Nutrient Data Laboratory home page, http://www.nal.usda.gov/fnic/ foodcomp.

17 Castillo C, Atalah E, Benavides X, Urteaga C. Food patterns among adults visiting primary care clinics in the metropolitan region. Revista Medica de Chile 1997; 125: 283-9.

18 Rozowski J, Cuevas A, Castillo O, Marin P, Strobel P, Perez D, et al. Differences in plasma antioxidants according to socioeconomic level in Chilean women. Revista Medica de Chile 2001; 129: 43-50.

19 Schmidt-Hebbel H, Pennacchiotti I, Masson L, Mella MA. [Chilean Table of Foods Chemical Composition]. Santiago: Facultad de Ciencias Químicas y Farmaceuticas, Universidad de Chile, 1992.

20 Masson L. [Updated Report on Omega-3 and Omega-6 Content in Chilean Foods]. Santiago: Facultad de Ciencias Químicas y Farmaceuticas, Universidad de Chile, 1997.

21 Holland B, Welch AA, Unwin ID, Buss DH, Paul AA, Southgate DAT. McCance \& Widdowson's The Composition of Foods, 5th ed. Cambridge: The Royal Society of Chemistry and Ministry of Agriculture, Fisheries and Food, 1991.

22 Department of Health. Dietary Reference Values for Food Energy and Nutrients for the United Kingdom. Report of the Panel on Dietary Reference Values of the Committee on Medical Aspects of Food Policy. London: Department of Health, 1991.

23 Food and Agriculture Organization (FAO)/World Health 
Organization (WHO). Energy and Protein Requirements. Report of a Joint FAO/WHO Ad Hoc Expert Committee. FAO Nutrition Meeting Report Series No. 52. Rome: FAO, 1973.

24 Bland JM, Altman DG. Statistical methods for assessing agreement between two methods of clinical measurement. Lancet 1986; 1: 307-10.

25 Chinn S. The assessment of methods of measurement. Statistics in Medicine 1990; 9: 351-62.

26 Chinn S. Statistics in respiratory medicine 2. Repeatability and method comparison. Thorax 1991; 46: 454-6.

27 Carnovale E, Marletta L. [Table of Food Composition]. Rome: Instituto Nazionale di Ricerca per gli Alimenti e la Nutrizione, 2002.

28 Resources Council, Science and Technology Agency, Japan. [Standard Tables of Food Composition], 5th ed. Tokyo: Ministry of Finance, 2000.

29 Menchu MT, Mendez H, Barrera MA, Ortega L. [Food Composition Table in Central America], 1st ed. Guatemala
City: Institute of Nutrition of Central America and Panama, 1996.

30 Food and Agriculture Organization (FAO). Energy-yielding Components of Food and Computation of Calorie Values. Washington, DC: FAO, 1947.

31 Sasaki S, Kobayashi M, Tsugane S. Development of substituted fatty acid food composition table for the use in nutritional epidemiological studies for Japanese populations: its methodological backgrounds and the evaluation. Journal of Epidemiology 1999; 9: 190-207.

32 Sanchez-Castillo CP, Dewey PJS, Aguirre A, Lara JJ, Vaca R, Leon de la Barra $\mathrm{P}$, et al. The mineral content of Mexican fruits and vegetables. Journal of Food Composition and Analysis 1998; 11: 340-56.

33 Pinochet H, De Gregori I, Lobos MG, Fuentes E. Selenium and copper in vegetables and fruits grown on long-term impacted soils from Valparaiso region, Chile. Bulletin of Environmental Contamination and Toxicology 1999; 63: $327-34$. 